\title{
INSPECTION OF FLOATING PLATFORM MOORING CHAINS WITH A CLIMBING ROBOT*
}

\author{
ALVARO RUIZ GARCIA ${ }^{\dagger}$ \\ Innovative Technology and Science Ltd (InnotecUK), \\ The Old Livery, Hildersham Road, Abington, Cambridge CB21 6DR, United Kingdom
}

TARIQ PERVEZ SATTAR

Centre for Automated and Robotic NDT, London South Bank University, 103 Borough road, London SE1 OAA, United Kingdom

This paper describes the development of Moorinspect, a novel robot that can climb on platform mooring chains both underwater and in air to non-destructively test (NDT) each link with long range ultrasound guided waves. The prototype robot is designed to be able to climb up/down a mooring chain for up to twenty metres below the surface, climb up through the splash zone to the first link which is located in air and connected to the turret of a Floating Production Storage and Offloading (FPSO) facility. This first link suffers the most intense stresses and fatigue failure and thus it is important to test its integrity. A robot that can climb through the splash zone (considered to be the most dangerous zone for human divers) will be the first of its kind. The robot is able to cope with link dimension variations due to corrosion and biological fouling and link curvatures caused by bent links, chain curvature due to gravity, and links twisted at angles of up to eight degrees around a nominal angle of ninety degrees. The robot places an NDT collar consisting of ultrasound probes around the full circumference of each link to be tested. The design has been analysed extensively using Von Mises stress analysis to ensure that the robot is strong and robust enough to carry a sensor payload of more than $70 \mathrm{~kg}$ and a robot weighing $500 \mathrm{~kg}$ in air and is able to operate in the splash zone. A first prototype chain climbing robot has been tested via trials on a four link mooring chain suspended in air and while immersed in a diving tank.

\section{Introduction}

\subsection{Mooring lines}

Mooring lines are safety-critical systems on offshore floating platforms [1,2]. A typical floating structure has as many as 14 mooring lines which is nearly $10 \mathrm{~km}$ of chain. The lines are subject to immense forces such as currents, oceans waves, and hurricanes. Other forces include impact with the seabed, abrasion, increased drag due to accumulation of marine organisms and salt water

\footnotetext{
* This work is supported by the European Research Agency. Seventh Framework Programme, Theme [SME-2011-1] Research for SMEs, MOORINSPECT, Grant Agreement No: 286976

${ }^{\dagger}$ Research supported by London South Bank University
} 
corrosion. Failure of one or more of these mooring lines can result in disastrous consequences for safety, the environment and production . One mooring line failure may cause the platform to capsize, but after multiple mooring failures the platform could drift away, losing control of the well-heads, which would not have chance to de-pressurise and ultimately causing the risers to rupture.

Therefore, periodical inspection of chain systems is mandatory for safety and early detection of possible faults. This is usually done either by stopping production, removing the links and testing them at quayside or by testing the chain system in water during the daily operation of the facility with minimal stoppage time. Huge cost savings can be made by not stopping production, decommissioning the chains and transporting them for off-shore testing.

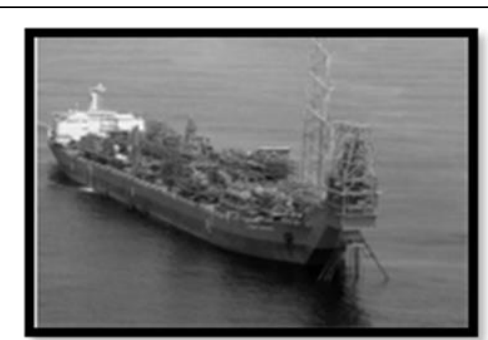

Figure 1. FPSO with mooring chains attached to a turret

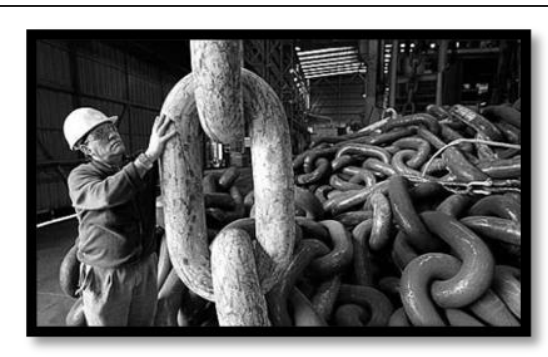

Figure 2. Example of a Mooring chain

\subsection{Current underwater inspection}

At present, underwater NDT inspections are carried out by means of expert divers and/or ROVs (Remotely Operated Vehicles). However, in-water inspection techniques are not very reliable. Identified anomalies are resolved with true confidence only by undertaking in-air inspection. Most ROVs provide in-water chain measurement using "Optical Calliper", which is currently accepted by a number of offshore certification bodies. They can distinguish between loose and tight chains using impact/ hydrophone with microaccelerometer and software. However, current ROVs systems cannot provide accurate component condition assessment that is essential to assess link integrity and condition.

The European funded Moorinspect project [3] has developed a robot called MOORINSPECT described in the next section that can climb both in air to test the first few links of FPSO chains (figure1) and underwater to deploy ultrasound probes that generate long range guided waves (LRUG). The aim is to increase the accuracy of in-water NDT testing with a method that can assess progressive wear and tear while the facilities are in operation. 


\subsection{The Moorin g chain environment}

The Moorinspect robot is required to climb on mooring chains (figure 2) that have link dimensions that range from 120 to $185 \mathrm{~mm}$ in diameter and from 720 to $1110 \mathrm{~mm}$ in height $[4,5]$. The robot has been initially designed to climb on $150 \mathrm{~mm}$ (diameter) studless mooring chain links. The weight of each chain link is around $250 \mathrm{~kg}$. The links are in a very harsh environment (seawater) which produces mechanical variations due to corrosion, biological fouling, link curvatures and misalignments between adjacent links. Corrosion and biological fouling effects produce an increase/decrease of the link dimensions.

There are two type of curvatures that may affect motion of the inspection capsule. The first (shown in figure 3) is due to the gravity effect, the length of the mooring chain and the distance between both ends of the chain. The second type of curvature is due to bending of a link (shown in figure 4). Twisting of a chain can cause misalignment between two successive links (see figure 5). Ideally, the angle between two consecutive links is 90 degrees. However, taking into account the chain movements produced by external forces, analysis indicates that this can vary by up to eight degrees.
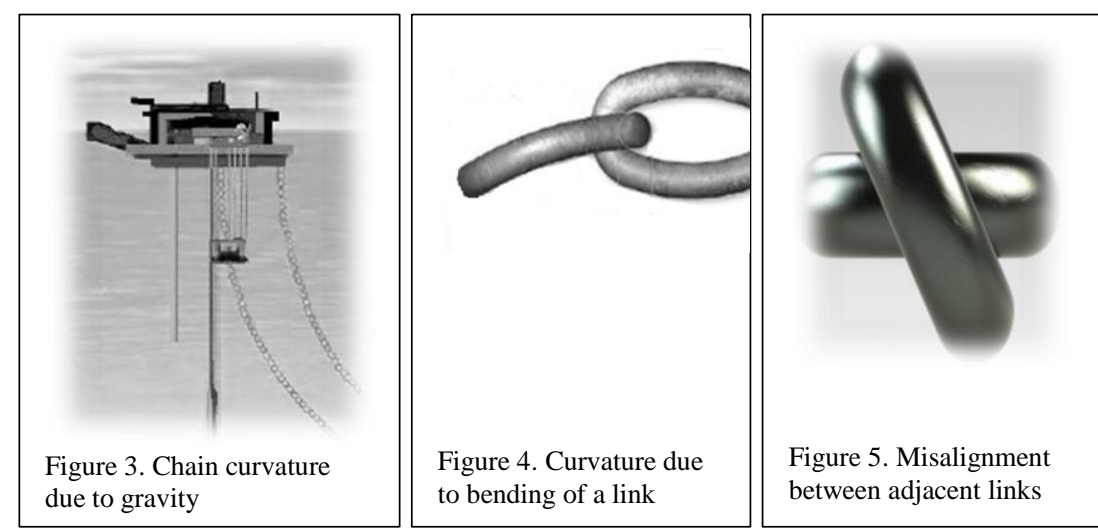

Figure 6 shows the range of link dimensions and the ideal angle of ninety degrees between two adjacent links. The climbing robot design therefore has to cope with a change of angle between successive links of nominally ninety degrees, variations in dimensions due to corrosion, biological fouling, chain curvatures and link misalignments. It has to lift its own weight and the weight of the NDT collar and its deployment system, counteract external forces produced by waves and tidal currents (especially in the splash zone) and the movements of the floating platforms. 


\section{The Moorinspect robot}

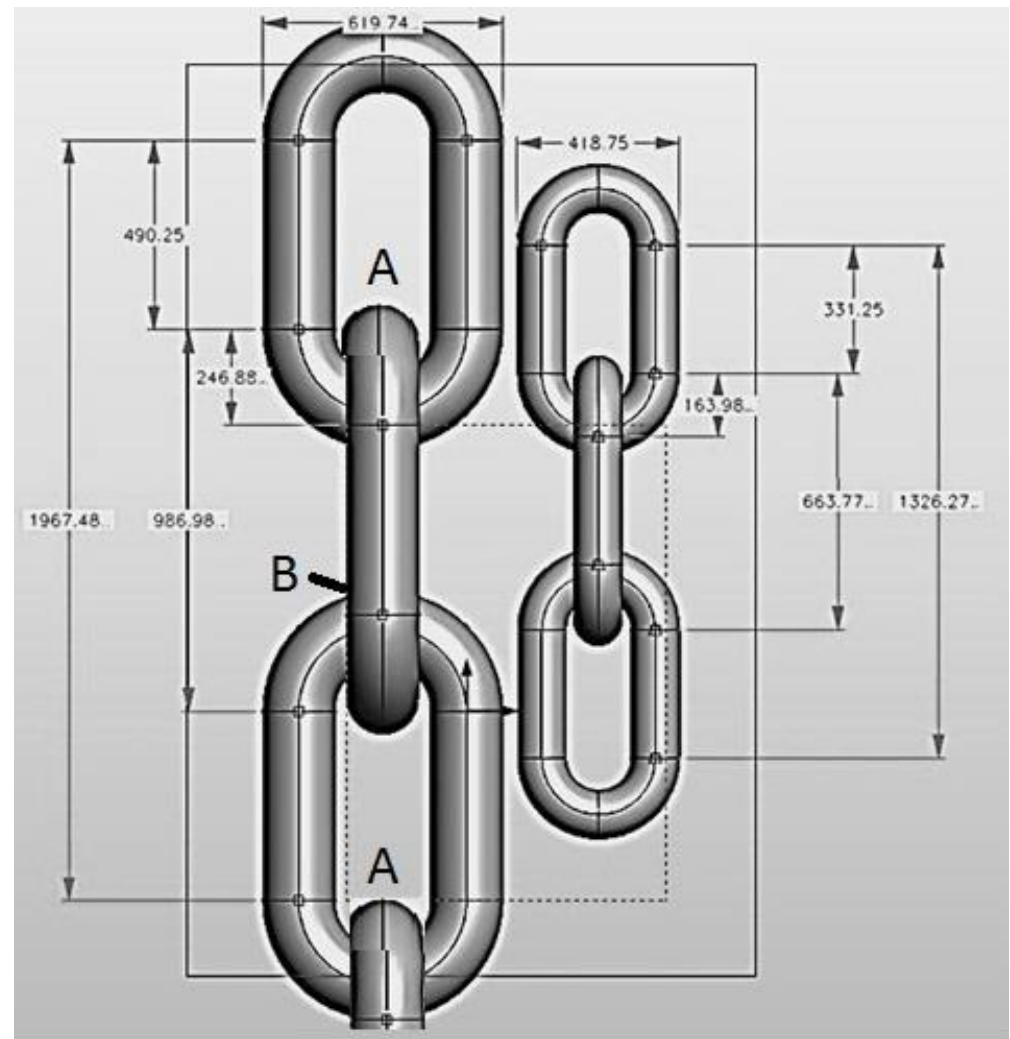

Figure 6. Range of Mooring chain dimensions

\subsection{The climbing starategy}

The climbing strategy is simple. The robot climbs up/down the chain using two "hands" that rest on top of each chain link to exert a lifting force. The rollers ensure that the hands are always able to get to the center of the frame. One linearly actuated hand is inserted into a link to rest on top of the link at point A in figure 6. The weight of the robot acts on this point. The hand is connected to an "arm" which is a vertical linear ball screw slide. A force to lift the capsule is generated by the arm by moving down the hand to increase the force on the mooring link. The inspection capsule will move up if the force is greater than the robot's weight, remain stationary if the force is equal and move down if it is less. A second hand (orthognol to the first arm) is moved up along the chain by a second linear "arm" and inserted to rest at point B. The hand at point A is then retracted and moved up to the next point A by the linearly actuated arm. The 
movements of both hands are completely synchronized with at least one hand that is always in contact with the chain. Additionally, both hands can be used at the same time to increase the lifting force

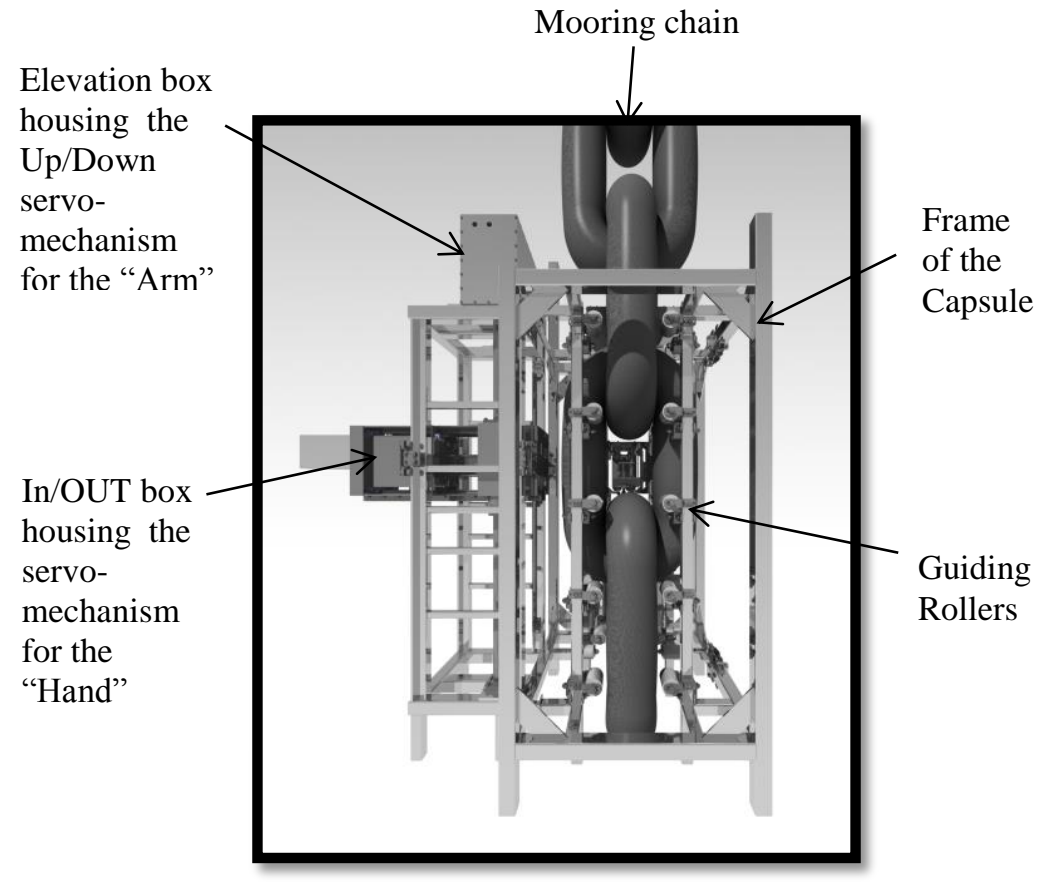

Figure 7. 3D drawing of the capsule enclosing a mooring chain

\subsection{Structural design}

The overall weight of the robot is around $500 \mathrm{~kg}$ and length close to 1.5 metre. These parameters have been used to calculate the strength of arm and hand beams and actuators required to lift the robot capsule. The overall structure of the inspection capsule is modelled with 3D and 2D Solidworks drawings (Figures 7 and 8 ) to perform a set of mechanical simulations from which the capsule is evaluated and improved during the design stage and before the manufacturing process.

Two mechanical stress analysis (Von Mises stress and displacement stress [8]) are used to analyze how the distortion energy is spread along the mechanical structure when one or several external forces are applied on it and how the structure will be deformed when the loads are applied. A safety factor of 2 is used to evaluate the design. 
The capsule is an aluminum frame that is welded to reduce the overall weight and increase structural robustness. The two lifting arms are manufactured from stainless steel. The frame size can be easily adjusted for each chain size. The capsule is divided in two halves to ease its installation and transportation. It is placed on the mooring chain and both halves are closed together with simple mechanical latches.

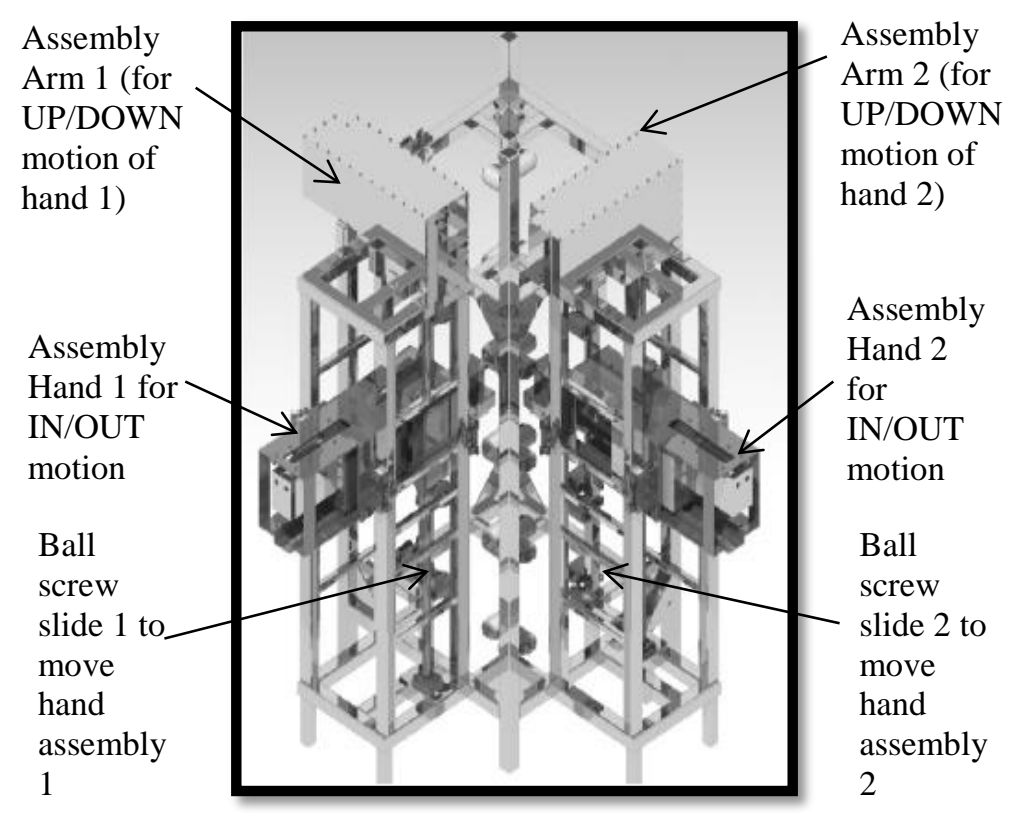

Figure 8. 3D drawing of the Moorinspect robot showing the IN/OUT and UP/DOWN assemblies

From the dimensions of the chain, the minimum length of the elevation arms is fixed around $400 \mathrm{~mm}$. A bigger length can be also selected but this affects the overall size of the capsule.

For the "hands" (Figure 9), which are critical load bearing structures, Von Mises stress analysis and displacement stress analysis is used to ensure that the maximum Von Mises value is lower than the Yield Strength limit. Sealed watertight boxes are used to house the IN/OUT motors and gearboxes (one per hand) and also to connect the hand beam to an elevation box. Their configuration and mechanical structure transmit or dissipate the remaining energy generated on the tip of the arm that cannot be dissipated on the beam.

The maximum displacement between the front wall and the lid is smaller than 0.1 millimeter even when the external force is equal to $10000 \mathrm{~N}$. A set of 
gussets are internally installed in all corners of the IN/OUT box in order to improve the dissipation energy performances and to reduce the likelihood of water leakages between the IN/OUT box and its lid due to the displacement.

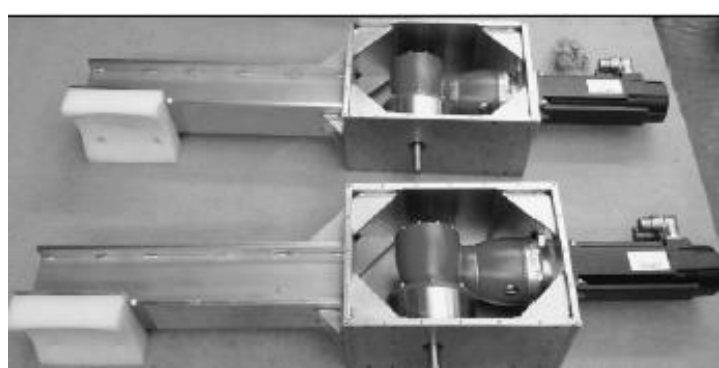

Figure 9: The "hands" comprising of shaped nylon resting pads, beams, and servo systems housed in water tight sealed boxes

Figure 9 shows the assembly process of the gearboxes, motors and nylon components of the capsule hands. The IN/OUT movements are driven by a horizontal rack-pinion system. The diameter of the pinion is $25 \mathrm{~mm}$ and its length is equal to $500 \mathrm{~mm}$.

Elevation boxes, manufactured with stainless steel, are used to move the hands up/down and also to transmit the dissipation energy from the hand to the rest of the inspection capsule. The up/down movements are done by means of a ball screw. The length of the ball screw is $1300 \mathrm{~mm}$ (Threaded length), its pitch is $10 \mathrm{~mm}$ and its diameter is $32 \mathrm{~mm}$. Both ball screws, one per arm, have been specifically manufactured for this application.

Two linear guides are placed on the top and another two on the bottom walls of IN/OUT boxes and are also bolted to the upper and bottom plates of the elevation boxes.

The rollers are bolted on the vertical structures and a set of holes are used to adjust their position before performing a new climbing process on a different chain.

\section{NDT collar deployment}

An NDT probe collar and a two axis deployment mechanism are installed on top of the inspection capsule but will not be detailed here. The collar is closed around the link using hydraulic actuators. Long range ultrasonic guided waves are pulsed around a link to determine its condition.

\section{Testing in air and underwater}

The Moorinspect robot was tested first on a 4-link chain suspended in air (Figure 10) using an overhead crane. The robot climbed the chain easily with 
another $100 \mathrm{~kg}$ of dummy load added to it. Two vision systems installed on the robot aided the insertion and placement of the hands. The robot was demonstrated climbing the 4-link chain in water in a diving tank. The prototype has demonstrated the feasibility of inspecting mooring chains in air and in water but needs a lot of further development before it can be deployed in a marine environment.
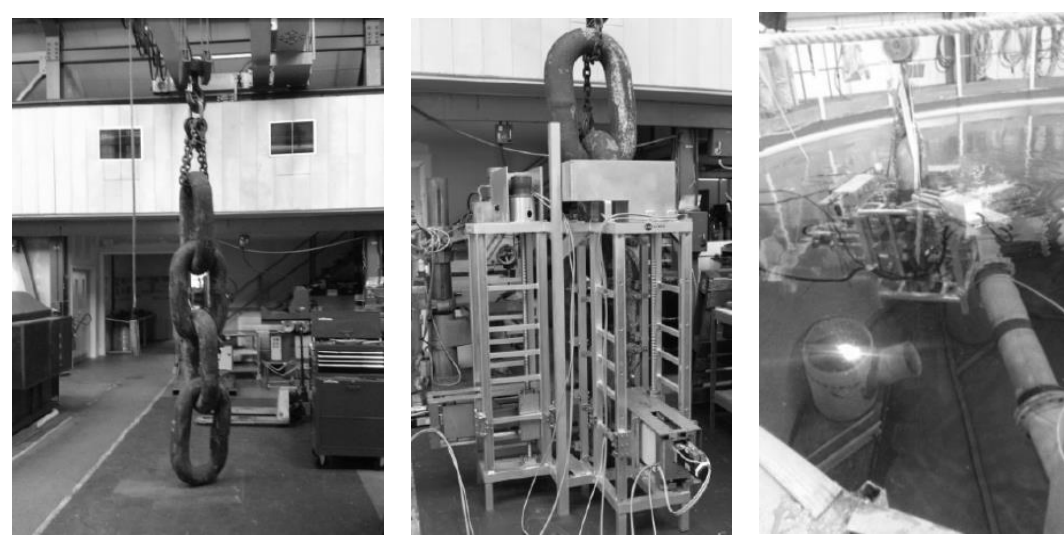

Figure 10. Robot prototype testing on the 4-link chain in air and underwater in a diving tank

\section{Acknowledgments}

Project funded by the EU FP7 Programme (see ref 3). The RTD performers were Plant integrity Ltd (UK), Ainoouchaou Pliroforiki Ae (Iknowhow Informatics S.A., Greece), Innovative Technology And Science Limited -Innotecuk (UK). The IP belongs to the SMEs: ByTest SRL (Italy), ORME SARL (France), Robotnik Automation SLL (Spain). Other end users were Vicinay Cadenas Sociedad Anonima (Spain) and Single Buoy Moorings INC SA (Switzerland).

\section{References}

1. Floating Production systems, JIP FPS Mooring Integrity, report by Noble Denton Europe Ltd. for the HSE 2006

2. Martin G. Brown, Floating Production Mooring Integrity JIP-Key Findings, Offshore Technology Conference USA (2005)

3. Seventh Framework Programme, Theme [SME-2011-1],Research For SMEs, Project Full Title: " Development Of An Advanced Medium Range Ultrasonic Technique For Mooring Chains Inspection In Water ", MOORINSPECT, Grant Agreement No: 286976

4. The future of Mooring, Vicinay Brochure Mooring Chain, R5 quality Steel Products PSR 2002:1, December 2009

5. SBM website: http://www.sbmoffshore.com/[Accessed on $20^{\text {th }}$ June 2012] 